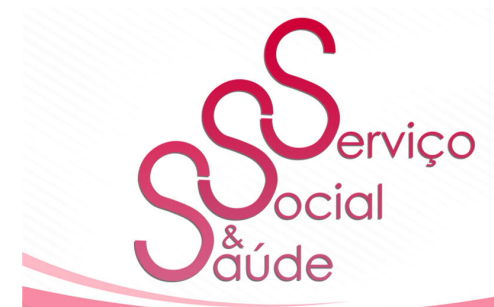

\title{
ALTA HOSPITALAR RESPONSÁVEL SOB A ÓTICA DO CUIDADO EM REDE
}

\author{
RESPONSIBLE HOSPITAL DISCHARGE UNDER THE PERSPECTIVE OF \\ HEALTH CARE NETWORK
}

\author{
Priscilla Fernandes Fagundes ${ }^{1}$ \\ Estela Márcia Rondina Scandol ${ }^{2}$
}

\begin{abstract}
RESUMO
O presente artigo tem como objetivo discutir o processo de alta hospitalar a partir da fala dos usuários e familiares egressos de uma unidade de Cuidados Continuados Integrados (CCI) sob a ótica do cuidado em rede no Sistema Único de Saúde (SUS). A alta responsável se configura como um processo no qual os usuários saem de um ponto da rede de atenção à saúde, no caso o hospital e são recebidos na atenção básica. Foi utilizada a metodologia qualitativa por meio de entrevista com questões abertas, com a participação de dezesseis (16) usuários, que receberam alta entre abril de 2016 a abril de 2017. Após a organização dos dados foram encontrados três (3) blocos de ideias que permitiram a análise, sendo: a) Leitura e compreensão do Relatório de Alta; b) Relacionamento com a rede de atenção à saúde; c) Melhorias possíveis. Assim, verifica-se a necessidade de aprofundar a discussão a respeito da alta responsável e sobre o papel do hospital como integrante de uma rede que se propõe ser horizontal e compartilhada em responsabilidades com os usuários do SUS.
\end{abstract}

PALAVRAS-CHAVE: Alta responsável. Hospitais. Redes de saúde. Serviço Social. Cuidados continuados.

\section{ABSTRACT}

The present article aims to discuss the process of hospital discharge from the speech of egress users and their families of a unit Integrated Continued Care (CCI) under the perspective of SUS network care. The high responsibility is configured as a process in which the users leave a point of the network of health care, in the case the hospital and are received in the basic attention. The qualitative methodology was used through an interview with open questions, with the participation of sixteen (16) users, who were hospital discharged between April's 2016 to April's 2017. After the organization of the data, were found three (03) idea blocks which allowed the analysis, therefore: a) reading and understanding of the discharge's report; b) relation with the RAS; c) possible improvements. Therefore, it's necessary a further discussion about responsible discharge and the hospital's role as a part of a network which proposes being horizontal and share responsabilities with the SUS users.

\footnotetext{
${ }^{1}$ Assistente Social, pós-graduada em Cuidados Continuados Integrados/UFMS/ESP. Instituição Origem: Universidade Federal de Mato Grosso do Sul (UFMS)/ Hospital São Julião (HSJ). Telefone: (67) 992791223. Email: priscilla_assistentesocial@hotmail.com.

${ }^{2}$ Assistente Social, Mestre em Saúde Coletiva, Doutora em Serviço Social. Escola de Saúde Pública de Mato Grosso do Sul (ESP). Campo Grande/MS. E-mail: estelascandola@yahoo.com.br. Telefone: (67) 98403-4983.
} 


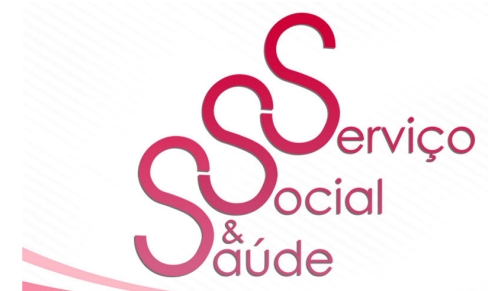

ISSN 2446-5992

(c) (i) (-)(2)

doi: 10.20396/sss.v0i0.00000000

KEYWORDS: Responsible discharge. Hospitals. Health's network. Social Service. Continuated cares.

\section{INTRODUÇÃO}

A saúde, como direito fundamental, é assegurada pela Constituição Federal (BRASIL, 1988) e foi regulamentada na criação do Sistema Único de Saúde (SUS) como um conjunto de ações e serviços, responsáveis pela promoção, proteção e recuperação da saúde (BRASIL, 1990).

O SUS, além dos princípios de universalidade e igualdade de direitos se fundamenta pela integralidade na atenção, cujos significados são: a) considerar a pessoa em sua totalidade, devendo as ações de saúde atuar sobre os fatores condicionantes e os determinantes sociais em saúde (BRASIL, 1990); b) considerar o acesso a todos os serviços disponíveis na rede de atenção à saúde.

$\mathrm{Na}$ perspectiva de responder ao princípio da integralidade, por muito tempo sedimentou-se a visão piramidal de organização do sistema de saúde, ou seja, a premissa da divisão em três níveis de complexidade onde o hospital era considerado como terciário e, portanto, o ápice da pirâmide (CECÍLIO, 1997). À atenção primária nessa visão era destinada a responsabilidade pela "porta de entrada" para os níveis de maior complexidade.

No nível secundário, estariam localizados os serviços como, os ambulatórios de especialidades, conjuntos de serviços de apoio diagnóstico e terapêutico, alguns serviços de urgência e emergência. Esse modelo de assistência piramidal, "nos coloca em uma armadilha nos sentidos [...] em fluxos hierarquizados de pessoas dentro do sistema" (CECÍLIO, 1997, p. 475). Essa visão ainda bastante utilizada no SUS trazia a herança histórica da maior importância dos hospitais em relação às unidades de saúde indicando hierarquização entre os serviços na atenção ao processo saúde-doença.

Foi no processo de construção do SUS e em seus tensionamentos internos que ocorreu o fortalecimento da atenção primária e se impôs a mudança do modelo de atenção à saúde e na critica a organização piramidal vem se construindo a concepção das Redes de Atenção à 


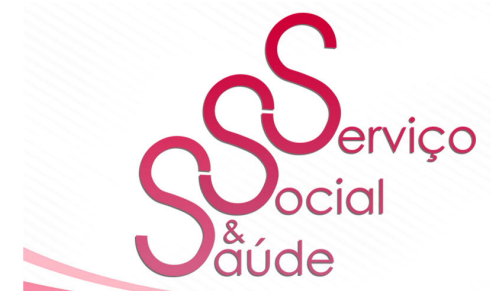

\section{ISSN 2446-5992}

(c) $)(9)$

doi: 10.20396/sss.v0i0.00000000

Saúde (RAS). Essa formulação refere-se a um conjunto de relacionamentos, uma malha, a qual possui relações relativamente estáveis e de natureza não hierárquica e independente (JUNQUEIRA e DAPUZZO, 2010). A reestruturação do Sistema Único de Saúde (SUS), na perspectiva de rede de atenção é uma estratégia de superação do modo fragmentado de operar a assistência e a gestão em saúde (BRASIL, 2010). Nessa forma de conceber o sistema aos hospitais é exigida a mudança nas relações com a RAS.

Segundo Mendes (2013) a substituição do modelo tecno-assistencial pelas RAS constitui a resposta adequada à situação de saúde vigente no Brasil e implica organizar de forma integrada sob coordenação da Atenção Primária à Saúde (APS), os pontos de atenção ambulatoriais e hospitalares secundários e terciários, os sistemas de apoio, sistemas logísticos e sistemas de governança. A singularidade das RAS é que o seu centro de comunicação situase na APS (MENDES, 2011), a qual se associa a um sistema em círculo, com movimento, no qual todos os serviços constituem-se porta de entrada e saída aos usuários (CECÍLIO, 1997).

O Hospital São Julião (HSJ), inaugurado em 1941 e sendo uma ex-colônia para hanseníase, tem passado por diversas modificações, não apenas internamente como também pela sua inserção no trabalho em rede. Desde 1970 com a chegada da "Operação Mato Grosso" e dos voluntários italianos, mesmo mantendo-se como referência para hanseníase, tem sido hospital de retaguarda para a rede estadual de atenção às urgências (ALVARENGA. 2014). Além de manter serviços ambulatoriais e cirúrgicos em resposta às necessidades de serviços demandados pela RAS, tem se constituído em cenário de diversas práticas de formação de trabalhadores para o SUS.

Em outubro de 2013, foi inaugurado no HSJ, o projeto Cuidados Continuados Integrados (CCI), já realizado em outros países como Portugal e Espanha, o qual têm o cidadão e a família como centro do sistema, cujos princípios visam considerar o âmbito social e de saúde dos usuários (ROHDE, 2013). Além disso, o Brasil aprovou a portaria 2809/2012, que estabeleceu a organização das Unidades de Cuidados Prolongados (UCP), registrando os hospitais como integrantes na RAS. Nessa perspectiva a unidade CCI/HSJ, tem sido uma das experiências da estratégia intermediária de cuidado entre os serviços hospitalares de caráter 


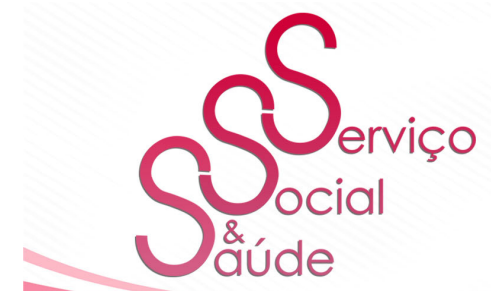

\section{ISSN 2446-5992}

(c) $)(1)(2)$

doi: 10.20396/sss.v0i0.00000000

agudo e crônico reagudizado e a atenção básica (BRASIL, 2012).

No mesmo período da contratação dos leitos destinados ao CCI, em 2013, foi aprovado o Programa de Residência Multiprofissional (PREMUS), vinculado a Universidade Federal de Mato Grosso do Sul (UFMS) com o apoio da Secretaria de Estado de Saúde (SES)/ Escola de Saúde Pública (ESP). A partir de então o PREMUS/CCI possibilitou a inclusão anual de seis (6) áreas profissionais, sendo: Nutrição, Enfermagem, Fisioterapia, Farmácia, Serviço Social e Psicologia.

O Projeto Pedagógico do PREMUS/CCI, estabelece que a participação dos residentes tem como fundamento as necessidades singulares em que os pacientes atendidos estão sujeitos e, com isso reafirma a importância da multidisciplinaridade envolvida no processo saúdedoença (UFMS, 2014). No CCI diferentes instrumentalidades foram adotadas, como: Acolhida, Projeto Terapêutico Singular (PTS), Visita Beira-Leito, Passeio Terapêutico, capacitação de cuidadores e Alta Responsável, sendo que em todas elas há uma ancoragem no processo educativo.

A alta constitui-se em um processo permanente, seja na relação dos hospitais de alta complexidade com o HSJ e deste com a rede de atenção básica. Portanto, desafiante e impactante para trabalhadores dos hospitais e para as pessoas internadas e em circulação pela rede. A Portaria 2809/2012 ao estabelecer a organização das UCP's dispõe como diretriz a alta responsável e a corresponsabilização da família no cuidado (BRASIL, 2012) e, portanto, desafia as unidades hospitalares a novas práticas e concepções no processo de alta.

Integrando a equipe multiprofissional o Serviço Social do cotidiano técnico-operativo trouxe em evidencia que a alta não se constitui em uma ação em si, ou seja, focalizada, mas constitui um conjunto de ações que estão em consonância com os Parâmetros para Atuação de Assistentes Sociais na Política de Saúde (CFESS, 2010). A alta hospitalar possibilita o exercício de diferentes atribuições como o atendimento direto aos usuários e seus familiares com ações socioassistenciais e socioeducativas; articulação com a equipe do hospital e mobilização de recursos intersetoriais. Portanto, pesquisar esse tema constitui-se em um espaço potencial de colaboração da profissão com o SUS na perspectiva da garantia dos 


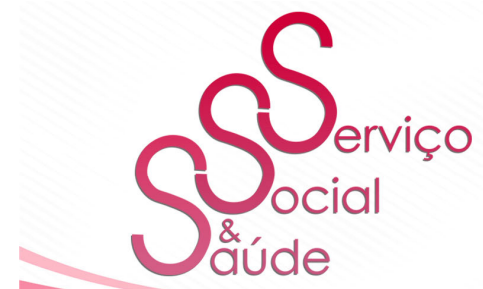

ISSN 2446-5992

(c) (i) (2)(2)

doi: 10.20396/sss.v0i0.00000000

princípios defendidos pela reforma sanitária e pelo projeto ético político da categoria.

Nessa perspectiva, objetiva-se com esse artigo discutir o processo de alta hospitalar responsável a partir da fala dos usuários e familiares egressos do CCI.

\section{METODOLOGIA}

A presente pesquisa utiliza-se do estudo qualitativo com base em dados primários que segundo Minayo (2006, p. 57), tal metodologia "se aplica ao estudo da história, das relações, das representações, das crenças, das percepções e das opiniões [...]”.

A escolha por essa abordagem foi motivada pelas diferentes questões que envolvem os egressos do programa de Cuidados Continuados Integrados (CCI). O contexto dos participantes faz parte da proposta de análise desse estudo, pois a singularidade de cada situação permite considerar as condições que envolvem a particularidade do que é a movimentação das pessoas entre a internação hospitalar e as redes de serviços, mediada pela alta responsável.

A pesquisa foi desenvolvida com os usuários de ambos os sexos, maiores de 18 anos e seus familiares, que receberam atendimento na unidade CCI do Hospital São Julião, cuja alta ocorreu entre abril de 2016 a abril de 2017 e o domicílio esteja registrado no Distrito Sanitário Norte de Campo Grande/MS.

A escolha por esse Distrito Sanitário teve como base o Projeto Pedagógico do PREMUS/CCI que definiu como cenários de prática possíveis esse território (UFMS, 2014), posto que o HSJ também o integra.

Foram excluídos deste estudo pessoas com comprometimentos neurológicos e cognitivos que impossibilitaram a comunicação verbal ou ainda, usuários que foram transferidos para hospitais de agudos, durante a internação, sem retorno ao CCI.

Foram atendidos neste período cento e trinta e oito (138) usuários, dos quais vinte e cinco (25) residiam no referido território. Nove (9) não participaram desse estudo, devido a: hum (1) óbito; três (3) não localizados; três (3) não acessados por viagem ou internação e dois 


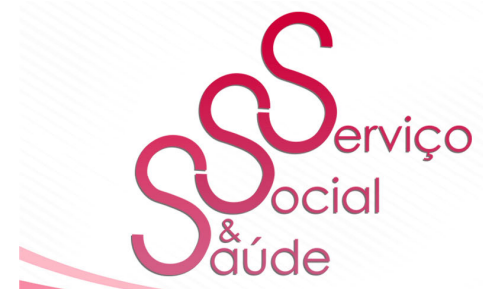

ISSN 2446-5992 (c) (i) (2)(2)

doi: 10.20396/sss.v0i0.00000000

186

(2) sem comunicação verbal. Dentre os dezesseis (16) egressos participantes da pesquisa, oito

(8) deles responderam individualmente e oito (8) contaram com a participação de familiares.

A coleta de dados do estudo foi dividida em dois momentos: a) o levantamento dos prontuários dos egressos, com: identificação dos usuários, telefone de contato e endereço, conteúdos da pré-alta e alta visando uma compreensão abrangente das ações realizadas; b) entrevistas gravadas com visitas previamente agendadas no domicílio ou no hospital, conforme decisão dos entrevistados.

As entrevistas foram realizadas por meio de questões abertas, as quais não se limitam "ao fazer do povo objeto passivo de sua investigação" (FREIRE, 1982, p. 118), mas que considera o pensar e saberes dos usuários entrevistados, ou seja, partícipes da construção do conhecimento.

As entrevistas foram gravadas e posteriormente transcritas, sendo o seu acesso somente à pesquisadora e orientadora. A pesquisa foi aprovada pelo Comitê de Ética em Pesquisa (CEP)/UFMS sob o número de parecer: 1.994.240. Foram dados nomes fictícios visando personalizar os participantes.

Os dados coletados nas entrevistas foram organizados por temas, com base na abordagem de análise de conteúdo que tem a finalidade de explicar e sistematizar as mensagens, significando as mesmas a partir de sua origem com seus contextos evidenciando as temáticas.

Utilizamos três etapas que envolvem essa metodologia de organização e analise de dados: Leituras sucessivas das entrevistas coletadas com seleção prévia dos eixos e categorias identificadas; organização dos dados a partir dos eixos e categorias confirmados e reescritos; analise dos dados buscando "ultrapassar o nível do senso comum e do subjetivismo na interpretação e alcançar uma vigilância crítica” (MINAYO, 2006, p. 308).

Ressalte-se que nessa perspectiva de pesquisa qualitativa o processo de leitura, organização e analise de dados constitui uma permanente reconstrução crítica de textos, na medida em que os eixos e categorias não existem em si, mas são confirmados e colocados em 


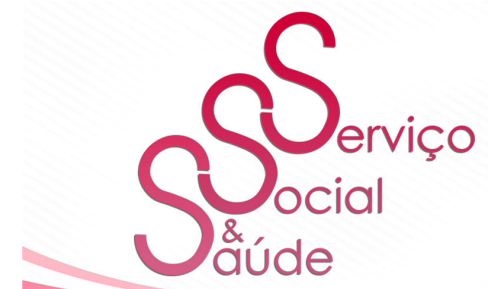

\section{ISSN 2446-5992}

(c) (i) (2)

doi: 10.20396/sss.v0i0.00000000

suspeição constante.

Cada parte é uma singularidade que se relaciona com o todo e as particularidades só são possíveis de serem compreendidas na perspectiva da totalidade, sendo suas contradições evidenciadas visando tornar visível a força que tensionam internamente o Sistema Único de Saúde (SUS) e, por conseguinte a política.

\section{RESULTADOS E DISCUSSÕES}

Um dos processos importantes dos Cuidados Continuados Integrados (CCI) refere-se ao momento de alta dos usuários. Desde a admissão na unidade do Hospital São Julião (HSJ), a equipe se organiza para possibilitar uma alta responsável, que segundo o art.16 da portaria 3.390, é “entendida como transferência do cuidado" (BRASIL, 2013).

A equipe multiprofissional do PREMUS/CCI e integrantes da residência clínica médica realiza o Projeto Terapêutico Singular (PTS), no qual são identificados os problemas, objetivos, plano de ação e responsáveis para cada situação/problema referente aos usuários e sua família.

Nesse procedimento registra-se o prognóstico de alta e a equipe se prepara para a sua realização estabelecendo, com a família, uma série de procedimentos a serem compartilhados. É possível afirmar que no CCI, a alta não é um momento específico, mas um processo que envolve a equipe o paciente e a família desde a chegada à unidade. Durante a internação processa-se também a interação com os demais serviços da rede de saúde e, no cotidiano do Serviço Social, a articulação com diferentes políticas sociais e, por vezes, a rede de garantia de direitos como a Defensoria Pública e Ministério Público.

No decorrer da internação são realizadas avaliações sobre a evolução das situações singulares, a partir do que foi sinalizado no projeto terapêutico singular e, assim, se monitora a data da alta previamente estipulada e a necessidade de alteração. Todos os procedimentos ocorrem com a participação dos usuários e seus familiares. 


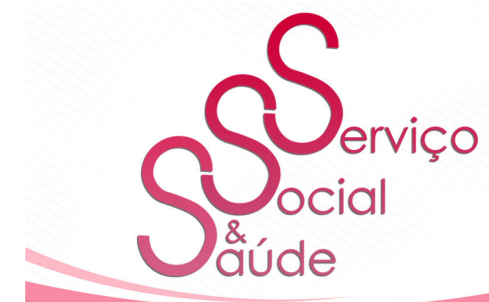

ISSN 2446-5992

(c) (i) (-)(2)

doi: 10.20396/sss.v0i0.00000000

Na finalização é elaborado um "Relatório de Alta" em que todos os profissionais que atenderam ao usuário registram suas intervenções e as necessidades de continuidade de atendimentos pós-hospitalar que, conforme a Portaria 2809/2012 deve "dispor das orientações adequadas ao usuário, cuidador e família” registrando a condição clínica e psicossocial (BRASIL, 2012).

Em Campo Grande foi pactuado entre o HSJ e a Secretaria Municipal de Saúde (SESAU) o envio de um relatório de pré-alta ao Distrito Sanitário, o qual realiza o encaminhamento à Unidade Básica de Saúde (UBS) que, acessando o histórico do usuário, pode se organizar para atender as necessidades desse no retorno ao domicílio.

Nos municípios do interior de Mato Grosso do Sul e outros estados ao assistente social cabe estabelecer o contato com o gestor local de saúde, explicitar a situação atual e o prognóstico de alta, bem como, discutir as condições de translado do usuário e família, sobretudo apresentar resumidamente o Relatório de Alta. Posteriormente envia-se por email cópia do relatório entregue ao usuário.

$\mathrm{Na}$ alta, além da equipe multiprofissional do PREMUS e clínica médica ocorre a participação das demais profissões de apoio matricial do HSJ que atenderam ao usuário como: fonoaudiologia, odontologia e terapia ocupacional. O relatório de alta é acompanhado de receitas médicas, cópias de exames e encaminhamentos aos serviços de saúde. O referido documento é entregue em um envelope identificado com o nome do usuário, contendo: a) cópia completa para o usuário e sua família; b) cópia completa para os arquivos do Hospital. Todos os documentos são digitados e impressos, na perspectiva de dar maior segurança às informações, evitando assim, equívocos advindos da caligrafia, ou seja, um fator limitante para a alta responsável.

Em caso de outros municípios é enviada, por meio do usuário, uma cópia completa para a gestão municipal de saúde. Sendo o usuário de Campo Grande/MS, em caso de encaminhamento para o Centro Especializado de Reabilitação da Associação de Pais e Amigos dos Excepcionais (CER APAE), é emitida uma cópia completa do relatório de alta para esse serviço. 


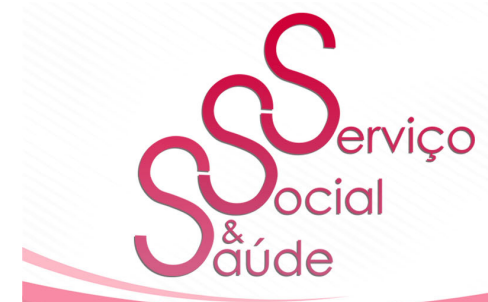

ISSN 2446-5992

(c) (i) (-)(2)

doi: 10.20396/sss.v0i0.00000000

Visando melhor evidenciar o processo de alta responsável a partir da visão dos usuários e familiares, podem-se observar três eixos que abarcam o conteúdo dos discursos dos entrevistados:

\section{I - Acesso, leitura, discussão e compreensão do Relatório de Alta}

Ao serem entrevistados sobre o acesso aos documentos elaborados no âmbito do CCI, os usuários afirmaram que todos haviam recebido o Relatório de Alta. Nas respostas sobre a leitura após a alta, duas pessoas afirmaram que, além de lerem, levaram aos atendimentos:

[...] inclusive a gente apresentou nas consultas, nos outros profissionais, na Fisioterapia, no Urologista, a gente apresentou esses documentos e foi muito válido. (Filipe)

Sim, porque todo mundo acha assim, super completo [...] Todos, todos os profissionais ali, a [médica], foi a que fez a ultrassonografia do rim. Ela falou: Gente, que coisa bem feita! e ali está tudo. (Sebastião)

Sobre a leitura dos documentos da alta, observou-se que os usuários contaram com a participação de familiares, como filhos, esposos, mãe e, em diversos relatos, mais de uma pessoa, com diferentes discussões de conteúdo. Somente uma resposta indicou que a pessoa da família lê, mas o usuário não.

\section{Minha mãe leu. (Sofia)}

É importante destacar a participação da família na leitura do relatório, pois esse é um aspecto significativo no que se refere aos egressos do CCI. Nesse modelo de atendimento a participação da família na internação é constante. Além de ser um dos critérios de inclusão no programa, a presença de um cuidador é fundamental na preparação da alta. Conforme Rohde (2013), uma das bases conceituais do modelo CCI concerne em fomentar a participação da família durante esse período de internação.

Dentre aqueles que discutiram o documento com os familiares temos depoimentos como: 


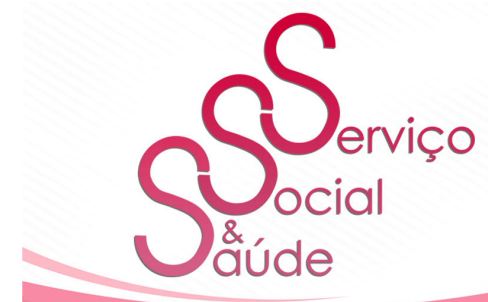

ISSN 2446-5992

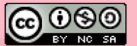

doi: 10.20396/sss.v0i0.00000000

190

Meu irmão leu [...] a gente conversou sim, sobre aquilo que tava no papel. [dúvida?] Não, não tive. (Raimundo)

Sim eu e minha esposa. [dúvida?] Não, tava tudo normal para compreender [...] tudo certinho, relatório de alta completo. (Frederico)

Eu li [...] conversei com os meus filhos e meu marido. (Silva)

Só a minha esposa que participa desses negócios. (Sebastião)

A minha filha leu. Tem algumas coisas que é tipo assim... as letras, porque é meio científico $[. .$.$] na medida do possível nós entendemos, né?. (Juliano e$ familiar)

A partir do conteúdo das falas, verifica-se que além da leitura, também ocorreu à discussão sobre o Relatório de Alta, considerando completo o seu conteúdo. É possível que tanto a família quanto com outras pessoas da comunidade possa ter ocorrido a troca de conhecimentos não somente sobre o período de internação como também sobre os encaminhamentos necessários.

No entanto, na entrevista do Juliano fica evidente que os termos técnicos no documento dificultaram sua compreensão. Essa afirmação nos leva a refletir sobre as diferentes funções do Relatório de Alta. Pode ser um instrumento para os encaminhamentos aos serviços, como também um cumprimento do direito às informações sobre o estado de saúde previsto na Carta de Direitos dos Usuários (BRASIL, 2013). Há de se registrar a hermeticidade das profissões como uma das dificuldades para o diálogo com as pessoas internadas e seus familiares, pois se percebeu que mensagens codificadas dificultaram o acesso às informações e sua compreensão. Essa realidade pode impedir a dialogicidade tão importante para a alta responsável.

Segundo Machado (2006), o saber propicia o exercício do poder, presente na escrita das profissões, as quais tendem a utilizar termos técnicos, para reafirmar seu conhecimento, não considerando o público a que se destina. $\mathrm{O}$ fato de somente esse usuário ter realizado essa afirmação não significa que os demais não tenham essa dificuldade. Sobretudo, pode significar que esse entrevistado ousou falar sobre algo que não era objeto da entrevista e, portanto, tem maior autonomia na relação com a entrevistadora ou mesmo com o hospital.

Apenas uma entrevistada realizou a leitura sozinha do relatório e, outros dois 


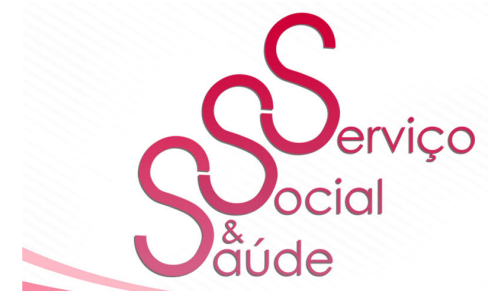

ISSN 2446-5992

(ㄷ) $190(0)$

doi: 10.20396/sss.v0i0.00000000

relataram que não realizaram a leitura:

Eu não li não [...] tá lá em cima guardado. (Antonio)

Não li. (João)

A partir dessas falas, observa-se que os usuários recebem o Relatório de Alta e os demais documentos no dia da saída do hospital e, no entanto, nem todos realizam a leitura e/ou discutem com a família sobre o seu conteúdo, mesmo sendo considerado pela equipe da PREMUS como um documento que trata do histórico e evoluções e tendo grande importância essa instrumentalidade no âmbito do CCI.

Como já afirmado anteriormente, a alta é um processo cuja preparação ocorre desde a admissão até a saída do hospital. É um momento em que o usuário e sua família estão repletos de preocupações como o cuidado no ambiente doméstico, aspectos financeiros, frustrações e expectativas com o prognóstico, continuidade dos atendimentos e os desgastes físicos e psíquicos decorrentes da internação, dentre outros. É nesse momento de tensão, tanto da equipe quanto da família que as orientações podem não ser compreendidas de forma efetiva, resultando em dificuldades para acesso aos bens e serviços pós a alta, como para a manutenção do cuidado.

\section{II - Alta e relacionamento com a RAS}

Observa-se que alguns usuários levaram o relatório aos atendimentos, e este foi importante e significativo visto que possui informações relevantes, podendo facilitar a continuidade da assistência iniciada no HSJ e contextualizando a situação clínica e psicossocial.

Sobre a importância das orientações dadas pelos profissionais do HSJ e visando ao acesso nos atendimentos necessários após a alta, dos dezesseis (16) entrevistados, seis (6) afirmaram terem sido suficientes, destacando-se os seguintes conteúdos dos discursos:

Foi a [médica] muito boa para mim, tinha muita paciência. [...] era muito pacienciosa, para me explicar, para me tolerar, porque já saiu encaminhado de lá, os pedidos foram encaminhados. (Vilma e familiar) 


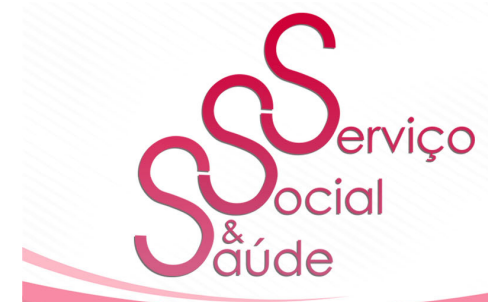

\section{ISSN 2446-5992}

(c) $)(1)(2)$

doi: 10.20396/sss.v0i0.00000000

Conforme o que foi enviado, aonde eu fui eu fui bem recebido. (José)

Foi tudo suficiente, foi à indicação perfeita. Agora o problema da saúde pública é que a gente demora muito para fazer [exames]. (Sebastião)

Explicaram certinho quando eu tava saindo do AVC e eu entendi. Falaram pra mim, perguntaram o que eu tinha no INSS, e eu disse que sabia, os intermediários do encaminhamento, já adiantaram bem o atendimento. (Raimundo)

Foi, gostei muito. Explicaram que tinha que ir na Casa da Saúde, ir lá na Sesau e, às vezes, até no fórum, Defensoria Publica. (Silvia)

Foi. Nossa! Tudo que elas falaram para mim, tudo que veio escrito eu consegui fazer tudo. Foi suficiente e eu não deixei também de ir para o médico, né? (Karina)

Conforme os relatos, as orientações recebidas facilitaram o acesso a bens e serviços de saúde, visto que foram bem esclarecidos quanto aos processos a serem realizados após a alta.

O usuário Sebastião relatou que foi bem orientado e encaminhado e, no entanto, há uma demora no acesso a estes serviços que, conforme Travassos (2004) a acessibilidade "refere-se às características dos serviços e dos recursos de saúde que facilitam ou limitam seu uso por potenciais usuários". Nesse sentido, o tempo de espera prolongado, limitou o acesso aos serviços. Além deste relato, outros dois (2) usuários não consideraram as orientações como efetivas, devido ao fato de não conseguirem os atendimentos:

Não, não [...] Por que ta faltando a fisioterapia [...] Falei com a [UBS] e falaram, que só tem que esperar, eu acho que é falta de vaga, né? (Juliano)

Do INSS foi o único quando eu saí dali [que] eu consegui, porque fisioterapia, o alcoolista [CAPS] e esses outros exames não ligaram pra fazer não. (João).

Pode-se afirmar que para esses usuários a orientação suficiente dos profissionais está diretamente ligada à continuidade da assistência após a alta. Conforme Vasques (2013), "facilitar a continuidade assistencial de saúde e social quando o paciente retorne a casa" confere como um dos objetivos do planejamento de alta no modelo CCI.

Os hospitais não devem estar à parte da rede de serviços (BRASIL, 2011), visto que, compõem as redes de atenção à saúde (RAS), as quais conforme a Política Nacional de Atenção Hospitalar (PNHOSP) devem realizar a "articulação da continuidade do cuidado com 


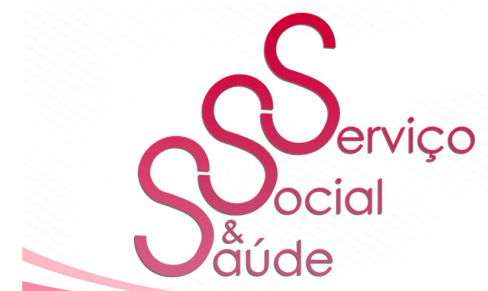

ISSN 2446-5992

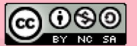

doi: 10.20396/sss.v0i0.00000000

os demais pontos de atenção da RAS, em particular a atenção básica" (BRASIL, 2013), garantindo assim, uma alta responsável por parte do hospital e, portanto, segura.

Ao serem questionados quanto à frequência à UBS antes da internação, a maioria afirmou que realizou exames de rotina e acompanhamento de doenças crônicas degenerativas, como diabetes e hipertensão. Um dos usuários, no entanto, relatou que raramente frequenta a UBS:

Não, nunca, raramente, eu fui um mês antes de ter o problema por causa da dor de cabeça, ai eles me consultaram, me receitaram uma tomografia paga ou pelo SUS, e os remédios. Aí eu continuei me automedicando até parar lá [Hospital]. (João)

Conforme já citado, as unidades de saúde recebem o relatório do hospital/CCI dias antes da alta, podendo assim preparar-se para receber o usuário na atenção básica sabendo o seu histórico de saúde/doença. Dos entrevistados, 2 possuem plano de saúde e afirmaram não utilizar o serviço público.

Graças a Deus, nunca precisei de atendimento público, eu toda vida trabalhei e tive meu plano de saúde e toda vida fui muito bem atendida pelo plano [...] Eu só vou no posto de saúde para tomar vacina contra gripe. (Karina)

Não, só para tomar a benzetacil, às vezes eu ia lá para pegar algum tipo de remédio [E exames de rotina?] eu faço pela pax. (Sebastião e familiar)

O fato de realizarem esta afirmação possivelmente se referiu ao complexo médico/hospitalar, onde são considerados apenas os atendimentos específicos médicos como sendo do SUS, pois, ao mesmo tempo em que relatam não utilizar o serviço público, citam que tomam a vacina, recebem visitas dos agentes comunitários de saúde (ACS) e utilizam os medicamentos disponíveis na rede. Há o entendimento que a saúde pública baseia-se apenas no atendimento médico.

Com base nas respostas à pergunta sobre se os egressos receberam algum contato ou visita dos profissionais da UBS próxima a sua residência, verificou-se que aqueles que conseguiram, tiveram esse serviço por meio dos ACS: 


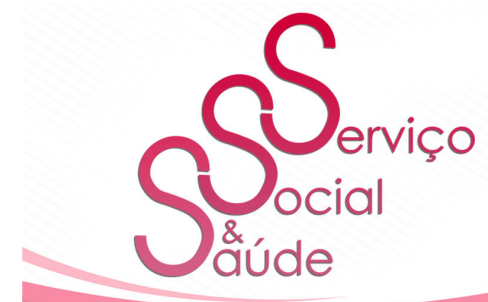

\section{ISSN 2446-5992}

(c) (1) (2) (-)

doi: 10.20396/sss.v0i0.00000000

Já, [Falaram algo sobre o São Julião?] eles falam: Você tem que cumprir certo com as coisas [O senhor sabe qual profissional que veio?] sempre que vem aqui aquela agente de saúde. (Antonio e familiar).

A agente de saúde e não veio mais ninguém [Ela falou algo sobre o São Julião?] Não. (Rodolfo e familiar)

Foi uma vez a agente de saúde, dessas que passa aí na rua, ai eu falei pra ela que tinha dado essa situação em mim e ai ela falou: vou mandar a assistente social falar com o médico pra ir uma vez por semana, mas não foi não. (Raimundo).

Observa-se na fala dos usuários que embora tenham recebido visita dos ACS, estes não tinham conhecimento da internação no HSJ. Confirma-se assim, a importância desses profissionais no que refere ao vínculo com os usuários e o desafio que está posto para a alta responsável. Houve ainda relato de um usuário que recebeu visita por ser vizinho de uma profissional da UBS,

Só a assistente social, [depois] a enfermeira chefe e a agente de saúde. É que ela mora aqui do lado. Aí ela sempre vinha, porque ela conhecia a gente e deve ter avisado alguém de lá pra vir até aqui. (João e familiar).

Esses conteúdos reforçam que os vínculos na atenção primária são mais significativos que os trâmites de documento. Para acessar os atendimentos os usuários relataram que procuraram a UBS:

Eu que tive que falar [São Julião], já vieram tirar sangue, fiz um exame de sangue. A Fisioterapeuta vem aqui de 15 em 15 dias. (Juliano)

Não, nunca ligaram. Quando eu saí do São Julião eu fui procurar o médico [UBS]. (Silvia)

Os médicos vem aqui, mas a minha esposa é que foi ali na unidade básica, e levou os documentos lá do São Julião. Aí eles vieram e como eu sou idoso eles vêm em casa. (José)

Os depoimentos confirmam que embora o Relatório de Alta seja enviado previamente, visando garantir a continuidade do cuidado esse trâmite formal protocolar, pactuado entre HSJ e SESAU não tem dado respostas efetivas, haja vista que nesses depoimentos, os usuários e/ou famílias necessitam procurar os serviços de seu território, ou buscar contato com profissionais da unidade para conseguirem acesso aos serviços de saúde. O Relatório e Alta 


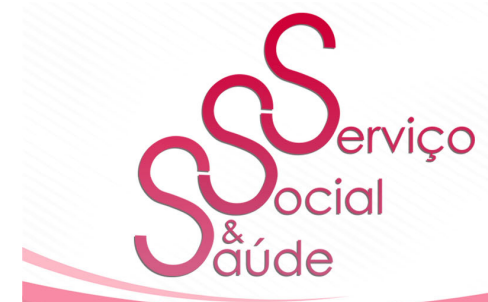

ISSN 2446-5992

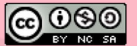

doi: 10.20396/sss.v0i0.00000000

parece ser mais uma responsabilidade burocrática do que propriamente a corresponsabilidade entre os serviços.

Nessa operacionalização da alta ocorre uma fragmentação nos serviços de saúde sendo que, os níveis de atenção, primário, secundário e terciário não se comunicam, nem tão pouco com os sistemas de apoio, impossibilitando a continuidade da atenção (MENDES, 2010). Percebe-se dessa forma, que mesmo com a discussão e os documentos do SUS apontarem para a importância da RAS, ainda permeia o conceito e a prática piramidal, onde há uma segmentação entre o hospital e os serviços externos a ele, incumbindo aos usuários a busca pelas suas necessidades de atenção.

\section{III - Possibilidades de melhorias na alta responsável}

Ao questionarmos sobre o que os usuários consideram que precisa melhorar no processo de alta, após o atendimento no CCI, tivemos que:

O que foi orientado lá para ela, que é da família, eu creio que nada. Não tenho o que falar em si do tratamento das enfermeiras, dos médicos. É fora de série... até as meninas que fazem a limpeza, sempre com sorriso no rosto. É assim que tem que ser. (Sandra - familiar)

Lá eu achei ótimo. Eu não queria nem vir. Bem da verdade, eu queria ficar lá. Eu ia ficar lá para acabar de restabelecer, poderia ter ficado. (Cássia).

Não há necessidade de melhorar nada, não, porque a equipe de lá trabalhou bem direitinho, fez tudo, a gente tem uma atenção muito grande. Todos os momentos que estava lá dentro se precisava de alguma coisa era só chamar que todo mundo nos atendia. No São Julião a vantagem é que eles ensinam a gente, eu falo para você: eu não tenho nada reclamar, nada, nada. (Sebastião - familiar)

Ah... pra mim tá tudo bom, tá tudo ótimo, fui bem atendido, são tudo amigo e tá ótimo. (Raimundo)

Em minha opinião, vocês fazem um trabalho muito bom com os pacientes. Eu e a minha esposa até elogiamos muito o tratamento, a gente gostou muito da atenção, melhorar eu não sei o que pode melhorar. (Filipe).

Nesta questão os usuários e seus familiares pontuaram positivamente sobre o atendimento recebido durante a internação no HSJ, interpretando assim a pergunta que não há necessidade de melhorias. Na fala do Sebastião e familiar é relatado sobre um dos objetivos do programa CCI, que refere a "promoção do envolvimento dos cuidadores nos cuidados" (CARRARA e DOLZ, 2013). 


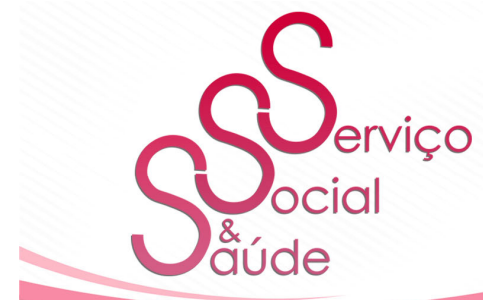

ISSN 2446-5992

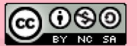

doi: 10.20396/sss.v0i0.00000000

A metodologia de atendimento no CCI, os vários profissionais, a ambiência do hospital, sobrepuseram em importância o processo de alta, refletida no conteúdo dos discursos dos usuários e suas famílias. Os problemas foram evidenciados no período pós-alta.

Dentre as entrevistas, as dificuldades no acesso a rede apareceu em um dos discursos devido à questão da burocracia:

Para falar bem a verdade, mas aí já entra na política, o sistema anterior era melhor. Por exemplo, antes de mudar para toda essa coisa de sistema de regulação e tal, eu combinava com alguém que ficava aqui com ela [mãe], eu ia sozinha lá no São Julião, acordava cedo e eu ia e marcava a consulta. Que dizer o atendimento era lá eu ia lá, marcava a consulta e no dia eu levava ela. Então era uma coisa muito mais simples, agora é muito burocracia. O sistema antigo era bem melhor. Tenho que contratar um dos meus filhos que venha dormir aqui ou que venham cedo [para transporte]. (Vilma e familiar)

A usuária Vilma e sua familiar consideraram que a continuidade da assistência após a alta, está correlacionada à burocracia do sistema de regulação (SISREG) do município, pois anteriormente agendava os atendimentos nas unidades, sem a necessidade de aguardar o agendamento por meio eletrônico, o qual dificulta segundo a usuária a dinâmica familiar. Observa-se nesse depoimento que a regulação por meio eletrônico desfez o vínculo direto com a unidade de atendimento, ou seja, construiu uma característica de impessoalidade nos encaminhamentos, pois o usuário não participa na decisão do melhor acesso, considerando: distância, horário, transporte, custo, alimentação e disponibilidade de acompanhante.

Um dos relatos sobre a continuidade de atenção a saúde explicita que:

Eu só acho que precisava melhorar, é que tenha um posto de atendimento que o CER APAE aqui mais próximo [...] Mais próximo daqui, porque é longe demais, o tratamento geralmente aqui tinha que ter na unidade próxima. (Marta).

A partir da fala da Marta, o serviço de fisioterapia deveria ser oferecido na unidade próxima a sua residência, de forma descentralizada, haja visto que os usuários atendidos no período desta pesquisa foram encaminhados via SISREG ao CER APAE, centralizando assim o atendimento. Além da distância, outra entrevistada, Sofia, afirmou que: 


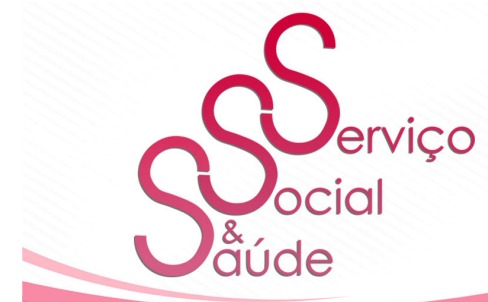

\section{ISSN 2446-5992}

Não precisa melhorar nada, só que a gente foi no médico já para perguntar sobre essa demora [Neurologista] e ela falou que tem muitos casos que duram ate dois (2) anos, porque demora mesmo né? Ela falou lá [UBS], igual teve casos que foi três (3) anos. Dai eu falei: Ah, então vou ter que me conformar porque demora mesmo. Eu sei que demora. (Sofia)

O conteúdo demonstra que há uma afirmação de não atendimento como regra e, que a espera esta naturalizada, inclusive citando a participação do profissional de saúde que pactua com a situação. O encaminhamento para as especialidade via SISREG criou uma fila eletrônica, cujo número de demandantes dos serviços não é conhecido pelos próprios usuários e profissionais. Assim não se sabe ao certo o tempo de espera ou mesmo a quem procurar.

Sobre o que consideram que é necessário melhorar no retorno ao domicílio referente a atuação do hospital, três (3) usuários relataram, que durante a internação, contaram com o suporte dos profissionais e, no entanto, após a alta não tiveram respaldo visando continuidade na RAS:

Até agora eu estou sendo bem tratado, não sei se é por eu ser idoso, mas eu tenho uma queixa: os médicos deveria vir acompanhar mais. Eles só vem só quando a minha esposa vai atrás e tem a agente comunitário e ai ela que leva. Os médicos do posto deveriam dar mais acompanhamento. (José)

O pós-operatório, isso que tem que melhorar, como que eu vou me recuperar? Lá foi sensacional o atendimento, as enfermeiras, os médicos, as fisioterapeutas, mas depois fica difícil, porque não continuou. (Juliano)

Lá [HSJ] eles cuidam de tudo, você sai de lá já fica mais difícil. Porque, enquanto ta lá é bem cuidado e aqui é cada um por si. (João)

Essas falas demonstram uma quebra no cuidado e o anseio pela continuidade após saírem do ambiente hospitalar. João pontuou que ao receber alta é "cada um por si". Essa fala nos remete a ausência da proteção social como sentimento de não pertencimento a um território de cuidado.

$\mathrm{Na}$ perspectiva do trabalho em rede as quais "necessitam aprofundar e estabelecer padrões estáveis de inter-relações” (MENDES, 2011, p.79), verifica-se uma lacuna assistencial, que segundo Scandola (2012) embora restrito, deveria o trabalho em rede pelo menos ser "um trabalho articulado por meio do qual uma pessoa/instituição só larga o bastão quando a outra o pega". Para a autora o trabalho em rede deve primar pela construção 


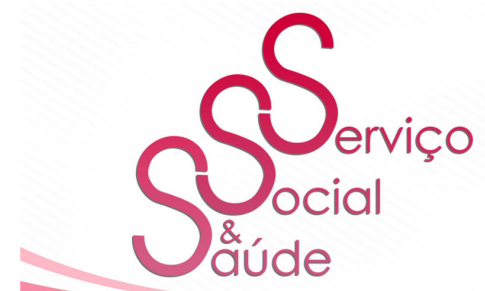

ISSN 2446-5992 (1)(0)

doi: 10.20396/sss.v0i0.00000000

permanente entre os serviços e pessoas na perspectiva que os usuários sintam-se parceiros entre no trânsito entre os diferentes pontos de atenção.

Além do acesso aos serviços, dois (2) entrevistados relataram sobre o acesso aos medicamentos:

O que precisa não tem jeito para mudar, porque o que precisa é de dinheiro. É porque tipo assim, no caso o medicamento não tem no posto você entendeu? E ele tem que comprar, recebe só uma vez por mês, então fica difícil, essa é a parte, né? Por causa do medicamento que várias vezes falta. Tem mês que não tem no posto e tem que comprar. Meu dinheiro não dá e eu fico sem. É complicado, né? (Antonio e familiar)

Eu acho que quando a gente sair do médico com as receitas dos remédios tem que ter na farmácia, nos postos [o problema] é mais a medicação, a gente tem que comprar né? só mesmo desses remédios caros que eu tive que estar comprando. (Silvia)

Os dois entrevistados que relataram sobre a medicação afirmaram que estão realizando a compra, pois essa não estão disponíveis na rede de atenção à saúde, chegando a cessar o uso por ausência de renda para custeá-la. A atenção medicamentosa ainda é fragmentada e percebeu-se que as receitas hospitalares podem ou não ser compatíveis com os medicamentos ofertados na rede básica. Observa-se nos discursos que não houve a busca pela garantia de direitos via judicialização.

Outro ponto que se destaca na fala dos usuários refere-se à possibilidade de receber um contato do Hospital quando eles retornam ao domicílio,

Assim... eu não posso falar... porque eu não tive mais contato eu não precisei de pessoas irem na minha casa. Nunca tive tipo assim, igual você perguntou tipo: você esta precisando de alguma coisa? um contato após a alta, como que está? Se, está precisando de alguma coisa, algum acesso a algum hospital vamos dizer assim né? Eu saí já com os encaminhamentos daqui e continuei, mas, depende da gravidade, mas seria importante porque nem todo mundo tem a possibilidade, às vezes, um acesso mais fácil, né? (Frederico)

Se tivesse no atendimento público, eu acho que eles deveriam comunicar que, por exemplo, eu sai do Hospital eu tive um AVC e que seria interessante alguém fazer uma visita, né? Eu graças a Deus não preciso porque eu tenho minhas condições, eu tenho meu plano de saúde eu sou esclarecida, minha família é esclarecida, a gente vai pro plano, mas se for uma pessoa menos esclarecida . Nunca tive nenhuma visita, entendeu? Independe de quem tem condições ou não tem, então eu acho que alguma 


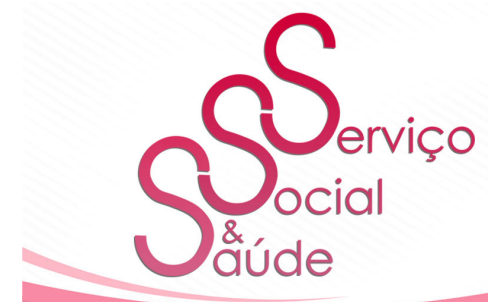

ISSN 2446-5992

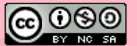

doi: 10.20396/sss.v0i0.00000000

coisa tinha que haver de lá [HSJ], uma visita para perguntar se está bem, se está precisando de alguma coisa. Eu não preciso porque eu sou esclarecida e vou atrás né? E tenho um bom plano de saúde mas se fosse uma pessoa que não tivesse teria ficado sem atendimento. (Karina)

A partir dos relatos dos usuários e familiares, observa-se que em geral o atendimento no CCI/São Julião foi positivo. No entanto, ao sair do hospital assemelha-se a um "desligamento" da rede e não um caminhar por ela. Embora no decorrer da internação, se estabeleça um vínculo entre usuários e familiares com a equipe profissional, na fala dos usuários esse se rompe no momento da alta. Os relatos são de grande relevância, pois o fato de não ter contato no período pós-alta com a equipe multiprofissional indica que os usuários não sentem o respaldo do hospital após a saída, o que pode se configurar como insegurança no cuidado em rede.

\section{CONSIDERAÇÕES FINAIS}

A alta responsável se configura como um processo no qual os usuários dos serviços de saúde saem de um ponto e são recebidos em outro da rede de atenção, diferente do conceito de alta que se baseia na perspectiva do desligamento. Nessa concepção o hospital é integrante da rede e como tal é partícipe da corresponsabilidade do que acontece com o usuário em toda a RAS, e não apenas enquanto está internado.

Referente à alta responsável que ocorre no HSJ, a fala dos usuários permite considerar que todos os egressos do CCI receberam o Relatório de Alta e realizaram a leitura com diferentes conteúdos entre amigos e/ou familiares, sozinhos e ainda houve os que não realizaram a leitura. Há que se destacar que esse documento necessita ser um exercício de escrita que seja de fácil acesso a compreensão dos usuários, pois se constitui em um instrumento de segurança para os usuários que ficaram internados e seus familiares, assim como a RAS.

Quanto ao relacionamento da alta com a RAS, os usuários consideraram as orientações recebidas no hospital efetivas, sendo que as informações contidas no Relatório de Alta foram significativas nos atendimentos posteriores, pois contempla informações importantes ao período da internação. Os usuários que não consideraram as orientações como efetivas 


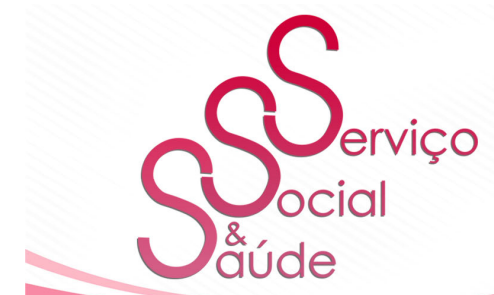

ISSN 2446-5992

(c) (i) (-)(2)

doi: 10.20396/sss.v0i0.00000000

relacionaram sua opinião com as dificuldades no acesso aos serviços e isso pode significar que a corresponsabilidade na alta precisa ser melhor discutida, não somente internamente no hospital como com em toda a rede.

No que se refere às melhorias da alta responsável percebe-se que os usuários ficaram bastante satisfeitos com os serviços realizados no hospital e pouco relacionaram isso com o processo de alta. Fica evidente que o atendimento recebido no CCI sobrepôs em importância aos desafios da continuidade do cuidado. Entre os relatos de possíveis melhorias, emergiu na voz dos usuários: a) Encaminhamento pelo sistema de regulação, não somente sobre a burocracia, mas também por não possibilitar o acompanhamento por parte do usuário do seu lugar na fila.

Observa-se que na atual forma de regulação o movimento causado pelas filas visíveis foi substituído por uma base eletrônica e com isso dificulta a pressão por parte dos usuários, movimentos sociais e da própria imprensa; b) serviços de fisioterapia em local centralizado e de difícil acesso aos moradores do Distrito Norte.

Além da distância os usuários não contam com serviços de transportes públicos suficientes com acessibilidade gerando custos para o acesso a esse direito; c) descontinuidade da atenção no retorno ao domicílio causando insegurança psicossocial como também econômica frente aos direitos da seguridade social; d) acesso aos medicamentos, nesse quesito refere-se tanto a falta de insumos básicos já padronizados como existente na atenção primária, como também aqueles medicamentos de alto custo cujo direito tem sido garantido a partir da judicialização em quaisquer situações há um processo de interrupção de uso, caso a família não os adquira por suas próprias expensas.

Respondendo ao que efetivamente pode ser realizado pelo hospital para melhorar a alta responsável, ficou como sugestão o contato com o usuário e sua família após a alta, todas essas falas dos usuários demandam mudanças nos procedimentos atualmente realizados, especialmente, considerando que o trabalho em rede necessita ser permanentemente construído na perspectiva da incompletude institucional e da compreensão que há um processo de resistência ao desmonte do SUS que é efetivado pelos trabalhadores do SUS e 


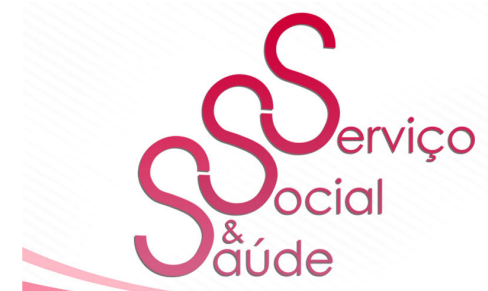

ISSN 2446-5992

(c) (i) (-)(2)

doi: 10.20396/sss.v0i0.00000000

pelos movimentos sociais, estimular o relacionamento como forma de fortalecer a RAS é uma tarefa para todos que primam pelo cuidado: trabalhadores, usuários e gestores em saúde.

Embora a articulação com a rede intra e intersetorial esteja de forma mais evidenciada no Serviço Social, discutir e responsabilizar-se pela alta responsável precisa ser um exercício de todas as profissões, atuar de forma coletiva impõe a todas as categorias o conhecimento e a ação para que o acesso aos direitos seja garantido como uma expressão ético-político e isso é um desafio na formação dos residentes pautada na metodologia problematizadora que impõe a ação no mundo da saúde.

A partir dessa pesquisa evidencia-se a necessidade de novos estudos sobre o tema, com os Distritos Sanitários e UBS/UBSF, a fim de verificar a realidade que não propiciou o cuidado com os usuários egressos de hospitais e, portanto a efetivação da alta responsável preconizada pela legislação e desejada pelos defensores do SUS. Necessita, além disso, aprofundar o papel do hospital como integrante de uma rede que se propõe ser horizontal, compartilhada em responsabilidades e de qualidade cumprindo os fundamentos da reforma sanitária.

Recebido em Fev. 2018 - Aprovado em Jun. 2018

\section{REFERÊNCIAS}

ALVARENGA, A. F. “O projeto piloto para implantação dos cuidados continuados integrados". In: DOBASHI, B. F. (org.). Tecendo redes na saúde para ampliar o cuidado. Campo Grande - MS. 2014.

BRASIL. Constituição da República Federativa do Brasil. Brasília DF. 1988. Disponível em: <https://www.planalto.gov.br/ccivil_03/constituicao/constituicao.htm>. Acesso em: 13 dez 2017. 


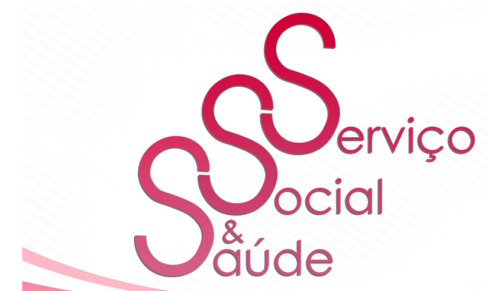

\section{ISSN 2446-5992}

(c) (i) (-)(2)

doi: 10.20396/sss.v0i0.00000000

BRASIL. Lei nº 8.080, de 19 de setembro de 1990. Dispõe sobre as condições para promoção, proteção e recuperação da saúde, a organização e o fundamento dos serviços correspondentes, e dá outras providências. Diário Oficial da República Federativa do Brasil, Brasília, DF, 20 set. 1990. p. 18055. Disponível em: < http://www.planalto.gov.br/ccivil_03/leis/L8080.htm> Acesso em: 13 dez 2017.

BRASIL. Ministério da Saúde. Carta dos direitos dos usuários da saúde / Ministério da Saúde; Conselho Nacional de Saúde - 4. ed. - Brasília : Ministério da Saúde, 2013.

BRASIL. Ministério da Saúde. Coordenação Geral de Alimentos e Nutrição (CGAN). Organização Panamericana de Saúde (OPAS). Observatório de Políticas de Segurança Alimentar e Nutrição (OPSAN). Universidade de Brasília (UnB). Curso de autoaprendizado. Redes de Atenção à Saúde no Sistema Único de Saúde. Brasilia. 2012. Disponível em: < http://www.redehumanizasus.net/sites/default/files/ras_curso_completo_1.pdf $>$. Acesso em: 13 dez. 2017.

BRASIL. Ministério da Saúde. Portaria nº 2.809, de 7 de Dezembro de 2012. Estabelece a organização dos Cuidados Prolongados para retaguarda à Rede de Atenção às Urgências e Emergências (RUE) e às demais Redes Temáticas de Atenção à Saúde no âmbito do SistemaÚnico de Saúde (SUS). Disponível em: < http://bvsms.saude.gov.br/bvs/saudelegis/gm/2012/prt2809_07_12_2012.html>. Acesso em: $13 \operatorname{dez} 2017$.

BRASIL. Ministério da Saúde. Portaria n 3. 390, de 30 de Dezembro de 2013. Institui a Política Nacional de Atenção Hospitalar (PNHOSP) no âmbito do Sistema Único de Saúde (SUS), estabelecendo- se as diretrizes para a organização do componente hospitalar da Rede de Atenção à Saúde (RAS). Disponível em < http://bvsms.saude.gov.br/bvs/saudelegis/gm/2013/prt3390_30_12_2013.html> Acesso em: 13 dez. 2017. 


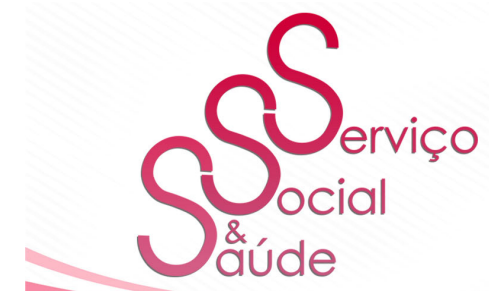

ISSN 2446-5992 (c) (i) (-)(2)

doi: 10.20396/sss.v0i0.00000000

BRASIL. Ministério da Saúde. Portaria no 4.279, de 30 de Dezembro de 2010. Estabelece Diretrizes para a Organização da Rede de Atenção à Saúde no Âmbito do Sistema Único de Saúde. Ministério da Saúde. Gabinete do Ministro. 2010. Disponível em:

$<$ http://bvsms.saude.gov.br/bvs/saudelegis/gm/2010/prt4279_30_12_2010.html >. Acesso em: $13 \operatorname{dez} 2017$.

BRASIL. Ministério da Saúde. Secretaria de Atenção à Saúde. Departamento de Ações Programáticas e Estratégicas. Atenção hospitalar / Ministério da Saúde, Secretaria de Atenção à Saúde, Departamento de Ações Programáticas e Estratégicas. - Brasília: Ministério da Saúde, 2011. 268 p., il. - (Série B. Textos Básicos de Saúde) (Cadernos HumanizaSUS ; v. 3) CARRARA. P; DOLZ. M. Tema 1. Linhas de Cuidados e Tipologias de Serviços. Projeto: Implantação de Experiências de Cuidados Continuados no Estado de Mato Grosso do Sul.

CEALAG. GESAWORLD. 2013. Não Publicado.

CECILIO, L.C. O. Modelos tecno-assistenciais em saúde: da pirâmide ao círculo, uma possibilidade a ser explorada. Caderno de Saúde Pública, Rio de Janeiro, v. 13, n. 3, p. 469-

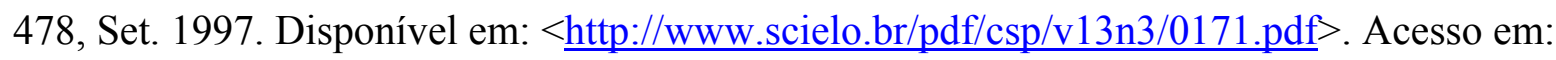
13 dez 2017.

CFESS. Parâmetros para Atuação de Assistentes Sociais na Política de Saúde. [Brasília]: Conselho Federal de Serviço Social, [2010]. Disponível em: < http://www.cfess.org.br/arquivos/Parametros_para_a_Atuacao_de_Assistentes_Sociais_na_Sa ude.pdf $>$. Acesso em 13 dez de 2017.

FREIRE, P. Pedagogia do oprimido. 11. ed. Rio de Janeiro: Paz e Terra, 1982.

JUNQUEIRA, L.A.P.; DAPUZZO, F. Gestão de Redes: A Estratégia de Regionalização da Política de Saúde. História Ciências Saúde-Manguinhos. v.17, p.545-547, 2010. Disponível em: < http://www.scielo.br/pdf/hcsm/v17n2/19.pdf>. Acesso em: $13 \mathrm{dez} 2017$.

MACHADO, R. 1942 - M133f. Foucault: a ciência e o saber/ Roberto Machado. - 3 ed. rev. E ampliada. - Rio de Janeiro: Jorge Zahar Ed., 2006. 


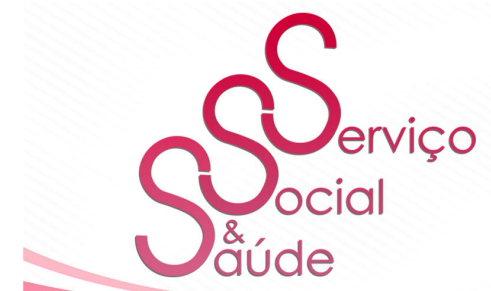

\section{ISSN 2446-5992 \\ (c) (i) (2)}

doi: 10.20396/sss.v0i0.00000000

MENDES, E. V. As Redes de Atenção à Saúde. Ciência Saúde Coletiva, v. 15, n. 5, p. $2297-$ 305. 2010. Disponível em: < http://www.scielo.br/pdf/csc/v15n5/v15n5a05.pdf > Acesso em: 13 dez 2017.

MENDES, E.V. As Redes de Atenção à Saúde. / Eugênio Vilaça Mendes. Brasília:

Organização PanAmericana da Saúde, 2011.549 p.: il. Disponível em: <

http://bvsms.saude.gov.br/bvs/publicacoes/redes_de_atencao_saude.pdf $>$. Acesso em: $13 \mathrm{dez}$ 2017.

MENDES, E. V. 25 anos do Sistema Único de Saúde: resultados e desafios. Estudos Avançados, São Paulo. v. 27, n. 78, p. 27-34, 2013 . Disponível em:< http://www.scielo.br/pdf/ea/v27n78/03.pdf>. Acesso em: 13 dez 2017.

MINAYO, M. C. S. O Desafio do Conhecimento: pesquisa qualitativa em saúde. $9^{a}$ ed. São Paulo: Hucitec, 2006.

ROHDE, E.B. Tema 2. Modelo de Cuidados Continuados Integrados no Estado de Mato Grosso do Sul. Estratégias de Apoio. Projeto: Implantação de Experiências de Cuidados Continuados no Estado de Mato Grosso do Sul. Secretaria Estadual de Mato Grosso do Sul (SES/MS). 2013. Não Publicado.

SCANDOLA, E. M. R. Bordar Telas: Integrantes do Viver. 2012. Biblioteca Virtual do IBISS. Disponível em: http://www.ibiss-

co.org.br/site/up/documento/2012_10_08/2012_10_08_15_14_47_0.pdf. Acesso em: 13 dez 2017.

TRAVASSOS, C; MARTINS, M. Uma revisão sobre os conceitos de acesso e utilização de serviços de saúde. Cad. de Saúde Publica [online]. Rio de Janeiro. v. 20. n. 2, p. 190 - 198. 2004. Disponível em: < http://www.scielo.br/pdf/csp/v20s2/14.pdf>. Acesso em: 13 dez 2017. UNIVERSIDADE FEDERAL DE MATO GROSSO DO SUL - UFMS. Projeto Pedagógico Residência Multiprofissional em cuidados continuados integrados. Campo Grande - MS. 2014.

VASQUES, O. Tema 2. Características e organização das unidades de internação de cuidados continuados. Projeto: Implantação de Experiências de Cuidados Continuados no Estado de Mato Grosso do Sul. Parc de Salut Mar e Gesaworld do Brasil. 2013. Não Publicado. 